\title{
A literatura contemporânea produzida na internet e no blog: características e marcas de autoria
}

\author{
Lucimara da Silva de Souza \\ Naiá Sadi Câmara ${ }^{\star \star}$
}

\section{Resumo}

$\mathrm{O}$ presente artigo consiste na análise e caracterização do texto literário produzido em blogs na atualidade, a partir das produções de novos autores que surgiram tendo esse espaço virtual como suporte. Após a avaliação de cinco crônicas, em que foram observadas as marcas de autoria e o trabalho com a função estética no texto, verificou-se a capacidade do suporte blog definir características diferentes para a literatura contemporânea presente na internet.

Palavras-chave: Blog. Autoria. Literatura.

\section{Introdução}

A internet é, acima de tudo, um meio eficaz de criação e difusão de informações, ideias e conhecimentos de todos os tipos, e não há fronteiras que impeçam qualquer cidadão comum de utilizá-la como aliada, seja para pesquisa, seja para consumo, produção e distribuição de conhecimento e cultura, de forma individual, coletiva e/ou compartilhada. Não existe limite de conteúdo na rede virtual e o usuário é quem faz as escolhas daquilo que quer ver, ler, ouvir,

\footnotetext{
* Mestranda em Linguística pela UFSCAR. Graduada em Letras Português-Inglês (2008) e especialista em Comunicação: linguagens midiáticas - Centro Universitário Barão de Mauá (2011), Ribeirão Preto/SP. Contato: lucimaras_souza@yahoo.com.br

** Doutora em Linguística pela UNESP - Araraquara/2003. Professora titular do programa de mestrado da Universidade de Franca. contato: naiasadi@gmail. com
}

Data de submissão: abr. 2013 - Data de aceite: ago. 2013 http://dx.doi.org/10.5335/rdes.v9i2.3854 
criar ou dividir com o outro. Múltiplas linguagens atendem a uma variedade enorme de sujeitos, e não há imposições de atividades pré-programadas que os façam navegar por aqui ou por ali. Os usuários buscam sempre mais, não são meros consumidores da informação. A possibilidade da interação e de todos se tornarem produtores de informação, além da liberdade de criação de conteúdos cada vez mais ricos é o que sustenta a grande rede mundial de computadores.

Para a recente literatura, a ferramenta também tem papel indispensável. A partir dessa tecnologia, uma nova geração de escritores passou a lançar seus escritos, seja para trocar experiências, como veículo de expressão ou para a difusão de informação. Hoje, qualquer cidadão sem conhecimentos de linguagem de programação pode criar um blog, escrever o que lhe convém, ler o que outros usuários escrevem, fazer contatos com escritores, compartilhar textos, fotos, vídeos, ideias, dentre outras possibilidades que a rede oferece. Todos podem, portanto, produzir conteúdos, compartilhar e, em poucos segundos, fazer qualquer informação alastrar-se pelo mundo.

A rede mundial de computadores, dentre tantas outras vantagens, vem promovendo a descoberta de talentos da literatura contemporânea, além de gerar a interação e o compartilhamento de informação em tempo real, processo anteriormente dificultado por barreiras geográficas de espaço e tempo.
E é sobre a produção literária na internet, especificamente a difundida em blogs, de que o presente trabalho irá tratar. A pesquisa pretende analisar e caracterizar o texto literário produzido em blogs na atualidade. $\mathrm{O}$ referido espaço virtual é um importante suporte para a criação do cidadão que pode ser considerado um novo autor da literatura contemporânea, mesmo ainda não sendo reconhecido oficialmente como tal.

Em outras palavras, tenciona-se avaliar o texto literário produzido no gênero digital blog na contemporaneidade, a fim de identificar características, como marcas de autoria e de processos de ressignificação por meio, sobretudo, do uso da função estética, objetivando verificar se essa ferramenta disponível na rede determina marcas linguístico-discursivas específicas.

Com isso, será possível abrir possibilidades de pesquisa acerca desse universo, com aprofundamento de discussões, já que ainda há muitos questionamentos sobre a produção literária na rede virtual. Afinal, a mudança de suporte, ou a supressão da materialidade do papel, gera uma escrita diferente - hipertextual, rápida, interativa - que provoca reações que vão do leitor ao crítico de literatura.

$O$ estudo, no que se refere ao conceito de autoria foi desenvolvido, especialmente, com base em contribuições de Foucault. Outros autores como Eni Orlandi, Sírio Possenti, Bakthin, dentre outros, foram leituras que auxiliaram no 
fortalecimento da fundamentação para 0 resultado do trabalho.

Autores como Hugh Hewitt, Denise Schittine, Octavio I. Rojas Orduña et al., além de artigos voltados à área de comunicação e escrita em internet deram sustentação à parte específica, e nomes como Antonio Candido, Afrânio Coutinho, Alfredo Bosi, René Wellek, Austin Warren, Beatriz Resende, Edson Cruz, Heloísa Buarque de Holanda, dentre outros, foram importantes para fundamentar a pesquisa quanto às expressões da literatura, da de informação até a contemporânea.

A opção por estudo de blogs deveu-se ao fato de essa ferramenta digital ter ganhado muito destaque ultimamente, pois, de espaço para simples relatos íntimos pessoais, passou a suporte para informações, expressão de ideias, formação de opiniões, divulgação de causas, revelação de talentos. Além disso, toda agilidade, rapidez, dinamismo e interação, próprios do meio, vieram responder às necessidades da contemporaneidade. Seu universo e cultura constituem a chamada blogosfera, aberta a todo tipo de internauta, na qual é possível compartilhar pensamentos e ideias sobre temas gerais, específicos ou pessoais, sem a preocupação com os cortes de um editor. Qualquer um, em qualquer lugar do planeta, a qualquer hora pode expressar, a seu modo, o que deseja por meio de sua escrita, podendo esse texto chegar, também, a qualquer pessoa nas mesmas condições.
A escolha por blogs de conteúdo literário justifica-se por acreditarmos haver, ainda hoje, poucos estudos que os abordem como espaço para criação de literatura. No Brasil, há milhares de blogs administrados por novos autores que surgiram somente a partir desse suporte; autores diferentes, quase sempre despretensiosos e muito talentosos, que não existiriam se não fosse essa ferramenta.

Do corpus selecionado para a pesquisa, fizeram parte blogs de conteúdo literário da Companhia dos Blogueiros de Araçatuba/SP, uma comunidade virtual que também mantém um blog e agrega membros/blogueiros com intenção de divulgar seus trabalhos, seus textos e/ou ideias. A escolha da Companhia deveu-se ao fato de ser um grupo fechado, ativo e gerido por uma coordenação, que possui ainda um conselho de ética e aproximadamente 490 membros/blogueiros cadastrados. Além disso, a comunidade é um dos poucos espaços virtuais brasileiros que reúne os blogueiros do país e recebeu, inclusive, em maio de 2010, uma premiação na categoria mídias livres - troféu cultural "Odette Costa"-, por meio do Conselho Municipal de Políticas Culturais de Araçatuba.

Após visitas diárias, dentre os blogs cadastrados na referida companhia, 5 (cinco) foram escolhidos para fazer parte desta análise, uma vez que atendiam às expectativas da principal proposta do trabalho. Três razões foram cruciais para essa seleção: 1 - os blogs deveriam 
ser da plataforma blogspot, por ser a plataforma gratuita mais popular entre os usuários; 2 - os blogs teriam que possuir, em maioria, postagens em prosa, no gênero crônica, com frequente atualização; 3 - os textos publicados deveriam ser, predominantemente, de autoria do próprio blogueiro.

Na primeira etapa de constituição do corpus, eliminou-se alguns blogs, uma vez que as razões 2 e 3 acima citadas foram bem observadas. Descartou-se, também, páginas cujos textos tiveram sua qualidade comprometida e perderam seu potencial criativo e literário em virtude do uso inadequado da língua portuguesa.

Para o presente artigo, foi selecionado um único texto com o objetivo de exemplificar a observação de características estéticas e marcas de autoria presentes. Trata-se do texto "Homens D40", do blog Virando jornalista, do jornalista M.F.

Considerando que os blogs tornaram-se populares em um contexto jornalístico, a preferência por crônica ocorreu pelo fato de ser o gênero literário mais próximo da linguagem jornalística. Os textos são mais curtos e tratam de assuntos da atualidade. Embora haja subjetividade, a escrita é, propositalmente, desprovida de rebuscamentos, o que faz do texto um convite ao leitor moderno que aprecia a leitura rápida, inteligente, com a qual se identifica.

Os blogs escolhidos e analisados são todos ativos, atualizados regularmente e pertencem a cidadãos comuns que, conforme perfis disponíveis em suas páginas, aparentemente desenvolvem a atividade sem maiores ambições, ou seja, escrevem por exercício da escrita ou por simples prazer.

Esta pesquisa é de grande relevância para a geração das novas mídias, que utiliza os blogs como meio de comunicação, expressão, interação e opinião. Afinal, a sociedade atual caracteriza-se pela busca da informação rápida, leitura mais dinâmica, além de uma relação mais íntima entre quem escreve e quem lê; a internet foi, portanto, responsável por diminuir essa fronteira que antes existia entre autor e leitor.

\section{O conceito de autoria}

Galli (2010) afirma que a linguagem da internet tem seus pressupostos que estão caminhando para um novo e/ou outro modelo de comunicação. E no campo literário não é diferente. A literatura reage às modificações. $\mathrm{O}$ antigo suporte, o papel, vem se apagando, a tecnologia e $o$ ato da criação misturam-se e resultam em "experiências que lidam com o efêmero" (RESENDE, 2008, p. 135). A escrita é mais breve, clara, direta e configura-se numa espécie de escrita oralizada, em tom mais próximo, atrativo e humano.

Dito isso, é evidente que nem tudo o que se publica nos blogs literários poderia ser publicado em livros, pois, na rede, um texto verbal, de caráter preciso e mais informal, mescla-se a outras linguagens, dialogando com imagens, sons e vídeos, 
produzindo conteúdos de rico sentido. Essa arte diferente existe a partir dessa linguagem plural, que não busca substituir o livro impresso, mas sim atender a uma necessidade do momento histórico em que se encontra a humanidade. Não há, dessa forma, apenas a transposição de um tipo de suporte para outro. O dobramento e desdobramento de um texto e/ou informações possível através das relações hipertextuais na rede definem, segundo Galli (2010), diferenças entre a interface da escrita (papel) e a interface virtual (tela) (MARCUSCHI; XAVIER, 2010, p. 153).

Várias discussões permeiam os canais de comunicação abordando a questão da literatura nos blogs ou de vários poetas e ficcionistas terem nascido a partir da internet, esse meio tão importante de difusão, criação e reflexão.

Em entrevista ao site Cronópios ${ }^{1}$, em 2007, Ana Peluso, escritora e designer, sobre os blogs e sua expansão, afirma que:

Hoje, lança-se um Blog como se lança um livro. Ou até mais. Acredito que infinitamente mais. Se isso é ruim? Claro que não. Isso, por um lado, é o que de melhor aconteceu para a literatura, para as artes, para qualquer tipo de expressão. Isso fez com que o concretista do sudeste conhecesse o cordelista do centro-oeste, tendo, ambos, como recurso extra, a opção de comentarem publicamente o que pensam, respectivamente, a respeito de suas obras. [...] A que isso pode levar? Ao triunfo da obra sobre o artista, e finalmente à liberdade de ambos [...].

Peluso (2007) ainda complementa afirmando que jamais se poderá dizer que a literatura está morta atualmente. Está mais viva, menos focada pelos canais que gerenciam conteúdo e mais aberta ao círculo social do autor, seus amigos, seus admiradores e seus críticos. Assim como na forma impressa, a literatura é delimitada por gostos, tendências, pensamentos similares, com a diferença de ser em quantidade maior e possuir o recurso da interatividade praticamente imediata.

Pensando nesse blogueiro que produz seu texto literário e publica por meio de posts em seus blogs para que todos tenham acesso, é importante pensar em sua condição de autor, ou novo autor, assim como as características de suas produções. Afinal, que literatura é essa levada para os blogs? O suporte define características específicas? Tais questionamentos serão discutidos ao longo da análise.

A produção na internet engloba, portanto, uma série de fatores, entre eles a autoria. Mas, como seria possível atribuir autoria a tantos indivíduos então desconhecidos? Haveria um processo de ressignificação do conceito de autoria para esse tipo de produção?

As inovações tecnológicas da contemporaneidade trazem muitas dúvidas diante do tema, possibilitando aos indivíduos comuns criarem cada vez mais, por isso, é viável que se repense a questão, tendo em vista um autor movido por um ideal expressivo (BARROS, 2010, p. 155).

O conceito de autoria na rede, como se pode observar, torna-se bem complexo, também pelo fato de conteúdos lançados na internet estarem sujeitos 
[...] à reescrituras múltiplas, à fragmentação, ao apagamento das marcas de autoria/autoridade de seu produtor; encontram-se, pois, expostos ao plágio, à imitação, ao empréstimo indevido. Os direitos (especialmente, os jurídicos) do autor se veem ameaçados por um processo de desmaterialização difícil de estancar. (CHARTIER, 1999, p. 67 apud KOMESU, 2004, p. 1).

A autoria, ponto que admitiu várias instâncias e conceitos ao longo da história, será aqui abordada partindo do conceito de Foucault, que afirma que a autoria é uma função "[...] característica do modo de existência, de circulação e de funcionamento de certos discursos no interior de uma sociedade" (FOUCAULT, 2002, p. 14).

A noção de autor, para Foucault (2002, p. 5), “constitui o momento crucial da individualização na história das ideias, dos conhecimentos, das literaturas, e também na história da filosofia e das ciências".

Ao relacionar autor e obra, o mesmo autor insinua que a função autor não existe sem a obra e afirma que essa é também função da escrita. Em seguida faz uma relação entre escrita e sujeito e defende que na escrita ocorre "uma abertura de um espaço onde o sujeito de escrita está sempre a desaparecer" (FOUCAULT, 2002, p. 7). Existe, então, uma associação do autor a um apagamento. Ele diz que

[...] a escrita está atualmente ligada ao sacrifício, ao próprio sacrifício da vida; apagamento voluntário que não é para ser representado nos livros, pois ele consumado na própria existência do escritor. [...] essa relação da escrita com a morte também se manifesta no desaparecimento das características individuais do sujeito que escreve; através de todas as chicanas que ele estabelece entre ele e o que ele escreve, o sujeito que escreve despista todos os signos de sua individualidade particular; a marca do escritor não é mais do que a singularidade de sua ausência; é preciso que ele faça o papel do morto no jogo da escrita (FOUCAULT, 2002, p. 7).

O autor estaria, então, anulando suas características individuais, porém, duas noções o preservariam: a noção de obra e a de escrita. A obra é insuficiente por si mesma, desligada de um autor - “a palavra 'obra' e a unidade que ela designa são provavelmente tão problemáticas quanto a individualidade do autor". Em relação à noção de escrita, poderia se afirmar que ela transporta as "características empíricas do autor.” (FOUCAULT, 2002, p. 9).

Foucault (2002) aborda também outro ponto interessante que é sobre o nome do autor, o qual é um nome próprio não como todos os outros, tendo em vista as diferenças:

[...] um nome de autor não é simplesmente um elemento em um discurso (que pode ser sujeito ou complemento, que pode ser substituído por um pronome etc.); ele exerce um certo papel em relação ao discurso: assegura uma função classificatória; tal nome permite reagrupar um certo número de textos, delimitá-los, deles excluir alguns, opô-los a outros. Por outro lado, ele relaciona os textos entre si; [...]. Enfim, o nome do autor funciona para caracterizar um certo modo de ser do discurso: para um discurso, o fato de haver um nome de autor, o fato de que se possa dizer "isso foi escrito por tal pessoa", ou "tal pessoa é o autor disso", indica que 
esse discurso não é uma palavra cotidiana, indiferente, uma palavra que se afasta, que flutua e passa, uma palavra imediatamente consumível, mas que se trata de uma palavra que deve ser recebida de uma certa maneira e que deve, em uma dada cultura, receber um certo status. (FOUCAULT, 2002, p. 13).

O nome do autor, de acordo com Foucault (2002), não transita, como o nome próprio, atrelado ao indivíduo produtor do discurso, mas sim a tipos de discursos cujos modos de ser numa sociedade ou cultura imputa a eles autoria. As mudanças na identidade de autor transformam, portanto, sua função no discurso, e nem todo discurso é dotado da função "autor". A função-autor vem marcar modos de existência, de circulação e de funcionamento dos discursos presentes na sociedade (FOUCAULT, 2002, p. 14).

Sobre os traços característicos da função autor, o pesquisador os resume assim:

[...] a função-autor está ligada ao sistema jurídico e institucional que contém, determina, articula o universo dos discursos; ela nasce se exerce uniformemente e da mesma maneira sobre todos os discursos, em todas as épocas e em todas as formas de civilização; ela não é definida pela atribuição espontânea de um discurso ao seu produtor, mas por uma série de operações específicas e complexas; ela não remete pura e simplesmente a um indivíduo real, ela pode dar lugar simultaneamente a vários egos, a várias posições-sujeito que classes diferentes de indivíduos podem vir a ocupar. (FOUCAULT, 2002, p. 20).

Partindo dessa perspectiva, poderiam ser chamados de autores apenas aqueles que apresentassem novidades de ideias e a quem se pudesse atribuir a produção de uma obra, texto ou livro, o que seria muito limitado, segundo Foucault (2002), que ainda restringe a noção de autor à noção de obra. O estudioso reconhece, na ordem do discurso, ser difícil estabelecer onde começa e onde termina uma obra, mas garante que a ideia de unidade é um fator categórico. (FOUCAULT, 2002, p. 21). Possenti (2002, p. 3) contribui afirmando que só existe uma obra se ela puder ser consistentemente associada a um autor e que a figura do autor é que estabelece a unidade a uma obra.

Consciente de ter dado ao autor um sentido "demasiadamente restrito", Foucault complementa afirmando que a função autor ocupa uma posição transdiscursiva, ou seja, a denominação autor estenderia-se também aos instauradores de discursividade, aqueles que produzem seus discursos a partir de um discurso inédito, como é o caso de Marx e Freud, por exemplo, que produziram "a possibilidade e a regra de formação de outros textos." (FOUCAULT, 2002, p. 21). E a instauração de uma discursividade é heterogênea às suas transformações posteriores.

Foucault (2002) assegura, também, que autor é apenas uma das categorias de sujeito enquanto produtor de linguagens, e que, historicamente, textos como narrativas, tragédias, comédias e epopeias, hoje tidos como literários, eram colocados em circulação sem o reconhecimento da autoria. $\mathrm{O}$ anonimato não era considerado dificuldade, e a antiguidade 
é que garantia a autenticidade. Já os textos de caráter científico somente eram valorizados se fossem marcados pelo nome do autor.

Ao longo do tempo, os textos passaram a ter autores:

Os textos, os livros, os discursos começaram a ter realmente autores (diferentes dos personagens míticos, diferentes das grandes figuras sacralizadas e sacralizantes) na medida em que o autor podia ser punido, ou seja, na medida em que os discursos podiam ser transgressores. (FOUCAULT, 2002, p. 14).

Além dessa condição de "apropriação penal”, analisa-se a historicidade como fator importante para a concepção do conceito de autor. A figura do autor mudou ao longo do tempo, pois passou a ser valorizada na medida em que a época exigiu identificação. Isso se deve à forma de interpretar a história da obra, do leitor e dos próprios autores, pois "a função autor não é exercida de uma maneira universal e constante em todos os discursos. Em nossa civilização, não são sempre os mesmos textos que exigiram receber uma atribuição" (FOUCAULT, 2002, p. 15).

Como o objeto de análise de nossa pesquisa é o texto literário, cabe citar a afirmação de Foucault sobre autoria em discursos literários: "a função-autor hoje em dia atua fortemente nas obras literárias" (FOUCAULT, 2002, p. 16). Para ele, a função-autor, dispensável nos discursos científicos por pertencerem a um sistema que lhes confere garantia, permanece nos discursos literários.
[...] os discursos "literários" não podem mais ser aceitos senão quando providos da função autor: a qualquer texto de poesia ou de ficção se perguntara de onde ele vem, quem o escreveu, em que data, em que circunstâncias ou a partir de que projeto. $\mathrm{O}$ sentido que lhe é dado, o status ou o valor que nele se reconhece dependem da maneira com que se responde a essas questões. E se, em consequência de um acidente ou de uma vontade explícita do autor, ele chega a nós no anonimato, a operação é imediatamente buscar o autor. $\mathrm{O}$ anonimato literário não é suportável para nós; só o aceitamos na qualidade de enigma. (FOUCAULT, 2002, p. 16).

Em resumo, ao longo de sua explanação na obra $O$ que é um autor?, Foucault traz importantes tentativas de definição. O autor é um "campo de coerência conceitual ou teórica" que mantêm uma unidade de escrita, é "o princípio de economia na proliferação do sentido" e princípio funcional "pelo qual se entrava a livre circulação, a livre manipulação, a livre composição, decomposição, recomposição da ficção." (FOUCAULT, 2002, p. 17). A função autor é exterior ao texto, ligada à sociedade onde é produzido.

Gregolin (2003) traz outra contribuição bastante coerente:

$\mathrm{Na}$ sua origem, o conceito de autor traz embutida a ideia de "aquele que se eleva diante dos outros". Dessa ideia deriva outra, a da autoridade. O poder da autoridade é obtido, pelo autor, através de seu saber. Enquanto detentor do conhecimento, o autor tem a autoridade para legitimar o seu texto e construir a verdade. Assim, nessa primeira concepção de autor, ele se eleva diante de todas as outras vozes: através do seu olhar, da sua subjetividade são organizados os sentidos e criado o sentido verdadeiro do texto (GREGOLIN, 2003, p. 2). 
Quando se fala em autoria, fala-se também em originalidade. Platão e Fiorin afirmam que "original é aquele texto que tem origem no indivíduo que o produziu, aquele texto que resulta de uma elaboração personalizada do enunciador e não de uma mera reprodução de clichês ou fórmulas pré-fabricadas." (PLATÃO; FIORIN, 1996, p. 359). Os autores ainda asseguram existir níveis de originalidade, e quanto mais alto o nível, melhor a produção. Nem todas as pessoas atingem a originalidade em suas produções, mas podem fugir dos estereótipos que acabam por desqualificar o texto, ou seja, podem evitar utilizar fórmulas prontas para expressão de sua percepção de realidade. $\mathrm{O}$ trabalho com a função estética também é outro fator que confere originalidade ao texto, pois ele tem maior valor se possui marcas de quem o produziu.

\section{Análise}

O texto a ser analisado é o "Homens D40", do blog Virando jornalista, do jornalista M.F.

O título já traz uma novidade na construção. A especificação D40 é atribuída aos homens como se estes fossem um artigo, um modelo com características próprias, um símbolo específico, representativo, uma forma comum a homens de uma mesma espécie, nesse caso, os homens de 40 anos de idade.

A postagem mostra um detalhe muito ?, articular dos blogs. Antes de iniciar o texto, o autor traz um breve comentário. O blogueiro menciona sua postagem an- terior e prevê a posterior, antes mesmo de escrever a crônica do dia. Seu objetivo é esclarecer a recorrência do tema nos três textos. É nessa proximidade e intimidade com o leitor que o blogueiro apoia-se para ter credibilidade. No mesmo comentário, também se utilizada da linguagem apelativa, expressa em "NÃO PERCA!" para seduzir esse leitor a voltar ao espaço para ler o próximo texto. A escrita espontânea o leva a brincar com seu interlocutor em "Raráh, só Jesus salva!".

Eu sei que este é o segundo texto em menos de quinze dias em que falo de uma situação que notei num bar e sei também que no próximo contarei algo que acontecerá na minha entrada para o "Alcoólatras Anônimos" NÃO PERCA! Raráh, só Jesus salva!

A crônica, propriamente dita, inicia com o marcador conversacional "mas", que funciona como um elemento de coesão. Embora seja uma conjunção adversativa, ela representa apenas a introdução ou, como em um bate-papo informal, busca dar continuidade ao comentário que precede o texto, tornando a linguagem mais dinâmica.

$\mathrm{O}$ primeiro aspecto bem evidente do texto é a utilização de espaços em branco. É um recurso muito utilizado em blogs que deixa o texto visualmente bem organizado, como se fossem blocos. Isso facilita a leitura e deixa a página do texto mais leve, muito mais quando se tem o bom gosto de combinar cor de fundo com cor de letras.

A imagem do blog também é bem convidativa, simplesmente por seu colorido e por se destacar na harmonia de cores da própria página do blogueiro. Além 
disso, serve de guia do conteúdo que será tratado na crônica.

É um texto de tema cotidiano, que traz uma crítica aos homens de 40 anos mal resolvidos em sua vida amorosa e que, como jovens, saem com meninas de 20 anos, as quais também são criticadas de forma bem-humorada pelo blogueiro.

A narrativa é em primeira pessoa e, desde o início, já indica uma situação bem específica, uma cena "em um bar com uma amiga no final de semana...”.

O humor se faz presente logo no primeiro parágrafo.
[...] percebi que lugares em que a especialidade é prato "a la carte" na hora do almoço e cerveja gelada após as três da tarde, os especialistas que frequentam esse habitat são os homens de 40. Daí pra cima. Os solteiros. $\mathrm{E}$ as barrigas, em geral, daí pra maiores.

O blogueiro ironiza o tipo de homem, o de 40 anos de idade e, ao caracterizá-lo, descreve com particularidade inclusive detalhes da roupa usada pelo referido tipo masculino. Esta ótica sobre os detalhes enriquece o texto tornando-o individual e original.

usam camisetas pólo com estampas em duas cores, com um " $\mathrm{X}$ " ou uma faixa transversal que divide as cores e um "brasão" costurado à esquerda ou direita do peito. Reconhece uma dessas? Pois é. Usando bermudas ou calças jeans, mas sempre com sapatênis ou tênis sem meia - regra! - outro acessório dos homens D40 são meninas D20.

Figura 1: Trecho do texto "Homens D40"

Fonte: http://virandojornalista.blogspot.com/2011/02/ homens-d40.html

Esse recurso é próprio de ambientes virtuais, pois implica não somente no processo de produção textual, mas também em nova forma de leitura. Segundo Di Luccio e Nicolaci-da-Costa,

[...] o hipertexto coloca o leitor contemporâneo diante de uma textualidade móvel e infinita que lhe permite fazer ajustes textuais singulares. É uma textualidade que nos remete ao mundo das navegações. Tendo a tela como suporte, navegamos de um texto a outro a partir de links." (2007, p.98 apud GRIGOLETTO, 2009, p. 2).
Estes homens D40

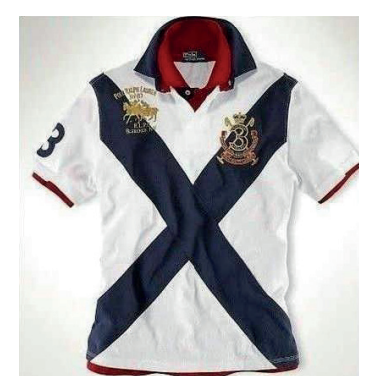

Figura 2: http://images01.olx.com.br/ i/4/83/97/1265914798_73287697_1-Fotos-de-faccao-de-camisetas-polo-e-malha.jpg

Na crônica estudada, o autor recorre novamente ao recurso do hipertexto quando fala de outro acessório dos homens D40: as meninas D20. São as meninas de 20 anos, sobre as quais M. F. já havia escrito em dezembro de 2010. Para levar o leitor a conhecer esse outro texto, cria novo hiperlink e faz a indicação. Com um único clique, o leitor pode, se desejar, chegar a um novo URL, ao endereço do outro texto, sendo um recurso utilizado, durante o texto, por quatro vezes pelo autor. 


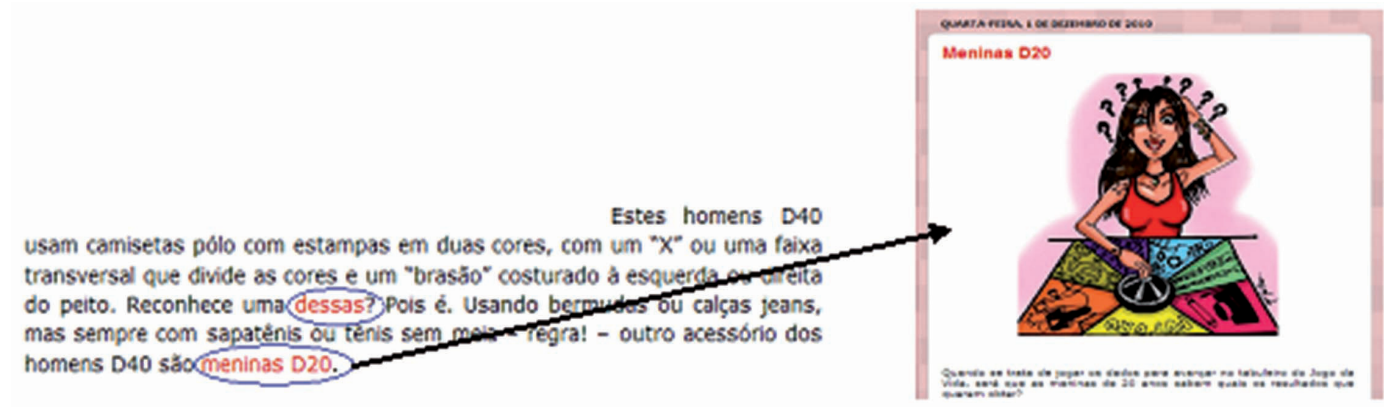

Figura 3: Trecho do texto "Homens D40"

Fonte: http://virandojornalista.blogspot.com/2011/02/ homens-d40.html
Figura 4: http://virandojornalista.blogspot. com/2010/12/meninas-d20.html
A produção textual nos blogs, esteticamente, diferencia-se da produção no papel. A possibilidade de o autor trabalhar com linguagens múltiplas extinguiu a estaticidade do texto impresso. Não há linearidade nem para o escritor, nem para o leitor. Do mesmo modo que o autor indica links, dando ao leitor a oportunidade de escolher seu caminho de leitura ou chegar a outras ideias, conceitos e informações, o leitor pode, mediante comentários, recomendar páginas ao blogueiro.

Em se tratando de produção literária na rede e dessa possibilidade da interconexão por meio de links - hipertextos - partindo de um único texto, recorrer-se a uma contribuição trazida por Barthes, em "A morte do autor" (BARTHES, 1984, p. 50 apud CAVALHEIRO, 2008, p. 5) Esse autor afirma que a escrita estaria libertada do absolutismo do autor pela possibilidade de o leitor também contribuir no processo de criação, seja adicionando uma informação ou alterando, estando extinta a ideia de uma escrita originária de uma única fonte, isso é, há dificuldade de se precisar o dono da voz que escreve - a escrita apagaria toda voz. Ainda assim, acredita-se não ser possível falar em morte do autor, mas sim uma nova concepção de autoria.

Retomando a crônica "Homens D40", nota-se a presença de frases curtas, de fácil entendimento e muito próximas da comunicação oral, características do gênero crônica.

No trecho "As conversas são apenas entre eles. As meninas... quais meninas? Essas sorriem e fingem estar interessadas no assunto, sempre olhando para esses homens com olhar de 'isso mesmo, meu amor, você é mesmo PHODÃO!' piscadinha com o olho ;)", dois pontos chamam a atenção: o primeiro é o uso do "predicado" "phodão", um atributo positivo, escrito em letras maiúsculas certamente para indicar uma alteração de volume de voz ou ênfase no significado, que constitui uma variedade linguís- 
tica, geralmente de um público jovem; o segundo é o símbolo ";)", um sinal de ponto e vírgula acompanhado de um de fechamento de parênteses, geralmente utilizado na linguagem virtual para facilitar a rapidez da informação. Nas plataformas de comunicação instantânea, esse recurso já faz parte dos textos e supõe um leitor conhecedor dessa linguagem. Esse sinal, dentro do contexto da crônica, significa uma garota de 20 anos, sorrindo e piscando um dos olhos. É uma marca da comunicação virtual e, no interior do texto, um recurso estático que marca a originalidade do autor na era da internet.

Prosseguindo a leitura, constata-se o uso da figura de palavra sinédoque a partir do termo "vagina" no trecho "Eles já sabem o que querem pra vida e pouco importa a vagina que os acompanha - que muda de tempos em tempos.”. A intenção de causar uma reação inesperada no leitor certamente foi atingida. O blogueiro consegue destacar o que é essencial no contexto, expandir o significado da palavra "vagina", completar a função referencial da linguagem e, consequentemente, torná-la mais expressiva. O sarcasmo obtido pelo conjunto configura-se numa crítica em torno da posição assumida pelos homens D40.

Embora haja o predomínio do discurso indireto, há uma passagem em que o discurso direto é marcado apenas pela introdução de dois pontos: "e depois disso: 'seremos apenas eu e meu super carro, com minhas manias, indo pras baladas com whisky e 'catando' todas". No mesmo trecho, é possível evidenciar novamente a linguagem oral. O blogueiro prefere utilizar "pras baladas" e " "catando' todas", em vez de "para as baladas" e "saindo com todas", respectivamente. A intenção é expressar uma linguagem própria do público jovem.

Ao final do texto, o autor faz um agradecimento a um blogueiro, responsável por desenhar as imagens - ou algumas imagens - de suas postagens, inclusive a que compôs a crônica "Homens D40". Esse registro está explícito ao leitor e configura-se numa marca individual do autor, possível nesse ambiente virtual.

$\mathrm{O}$ blogueiro $\mathrm{M}$. F. não foi o primeiro, tampouco será o último a escrever sobre os homens de 40 anos mal resolvidos e a futilidade das meninas de 20 anos, no entanto, ao ressignificar sentidos já estabelecidos por meio de seu olhar, criatividade, originalidade e sua subjetividade, atinge a autoria. Além de assumir sua responsabilidade pelo enunciado quando assina seu texto, posiciona-se ideologicamente na sociedade.

É por meio desses elementos somados à articulação de ideias que é possível detectar autoria. A forma de dizer foi muito particular e com uma das características mais importantes da literatura produzida em blog: a concisão.

Ao fazer a análise foi possível observar que há características específicas na literatura produzida na internet com o uso de uma linguagem híbrida, plural, repleta de recursos que torna popular 
em um espaço de tempo muito curto. Sendo assim, o escritor passa a criar seus sentidos e a organizar sua forma de dizer ao dominar e combinar várias linguagens, como a escrita, a oral, a visual, entre outras.

Quanto aos blogs, o próprio suporte já oferece a grande vantagem: o usuário pode ser o administrador, o escritor e o editor de sua página. Ali, pode publicar somente o que lhe convier e, ao conteúdo, agregar imagens, som, vídeos ou qualquer outro atributo capaz de estabelecer uma relação dialógica com a escrita, que tencione produzir algum sentido para 0 leitor, ou que o próprio leitor produza os sentidos. A liberdade, base da criação, vai da escolha da temática até a disposição estética do texto na página.

Pela internet, o autor de blog tem a chance, também, de criar a empatia e a cumplicidade com seu leitor, não havendo fronteiras entre ambos.. No texto em análise, o blogueiro, ao preceder sua publicação esclarecendo a recorrência da mesma temática em três textos, tem a intenção de seduzir aquele leitor para que esse volte outras vezes à sua página. Da mesma forma que avalia um livro impresso, no blog, por meio de visitas frequentes, o leitor vai se familiarizar com o estilo de escrita do autor. Nesse sentido, ambos se tornam críticos.

Essas postagens podem ser lançadas na rede a qualquer momento e são ordenadas em cronologia inversa, com as mais recentes primeiro, ficando arquivadas por tempo indeterminado.
Nos blogs analisados, os autores utilizaram imagens e cada qual se relacionou e constituiu um diálogo com o texto publicado, o que se evidencia também no blog escolhido como exemplo. Da mesma forma que as crônicas, todas a partir de fatos do cotidiano, apresentaram linguagem espontânea, criatividade e originalidade por meio também dos traços da oralidade próprios do gênero. $\mathrm{O}$ uso das figuras de linguagem e as conotações ofereceram qualidade aos textos.

A multiplicidade e o convívio de formas diferentes de escrever são as marcas da literatura contemporânea possibilitando a esse autor de blog inúmeras oportunidades para criação, dentre as quais, está a inserção de hiperlinks em algum ponto do texto, transformando-o em hipertexto. Esse recurso permite ao leitor a escolha de um trajeto não linear de leitura, além de tornar o ambiente bem dinâmico. "Ao utilizar a hipertextualização, o leitor tem a oportunidade de ampliar as ocasiões de produção de sentido e enriquecer sua leitura." (MARCUSCHI; XAVIER, 2010, p. 151).

Esse recurso, utilizado na crônica em análise, produz a polifonia, ou seja, outras vozes passam a atravessar o texto, tornando mínima a presença do autor. Conforme Foucault (2010), a função autor não deve ser confundida com o autor que escreveu o texto, uma vez que este deve ser entendido como "princípio de agrupamento do discurso, como unidade e origem de suas significações, como foco de sua coerência." (FOUCAULT, 2010, p. 
26). Gregolin (2003) afirma que a voz do autor é inscrita no texto por processos comunicativos, como uma voz entre as outras.

A crônica "Homens D40" foi seguida pela assinatura do autor do blog, recurso recorrente e observado nas demais páginas virtuais utilizadas na pesquisa. Esses textos não são, portanto, escritos que circulam na internet no anonimato, podem não ter relevância mundial, mas na blogosfera tem um funcionamento. Reiterando o que disse Foucault (2002, p.13), esses textos exercem certo papel em relação ao discurso, assegurando uma função classificatória. A condição de blogueiro e seu nome na blogosfera permitem reagrupar certo número de textos, delimitá-los, selecioná-los e opô-los a outros. Os textos são unidades e aos blogueiros é imputada a responsabilidade pelo dizer.

Portanto, pode-se afirmar que o nome do autor do texto "Homens D40", utilizado neste artigo, serve para caracterizar "um certo modo de ser do discurso" e não é uma produção transitória e sem importância (FOUCAULT, 2002, p. 13). O nome do autor carrega uma descrição, mantém o estilo e a qualidade que admite identificá-lo, e sua obra, de algum modo, possui estatuto. É aí que a função autor apresenta-se como uma característica do modo de existência, de circulação e de funcionamento de certos discursos no interior de uma sociedade. Pode-se, aqui, também falar da relação com a função-sujeito, pois, a função autor pode dar lugar a vários egos, "a várias posições-sujeitos que classes diferentes podem vir a ocupar". (FOUCAULT, 2002, p. 20).

Todo texto literário é dotado de função estética. E a significação do texto depende da atuação do plano de expressão sobre o plano de conteúdo, pois "o escritor não apenas procura dizer o mundo, mas recriá-lo nas palavras, de modo que, nele, importa não apenas o que diz, mas como se diz" (PLATÃO; FIORIN, 1996, p. 351).

$\mathrm{O}$ autor em questão, como outros autores de blogs, com suas particularidades, consegue instalar valor artístico à trivialidade do dia a dia.

Com base nas marcas de autoria e observação da função estética nos textos publicados nos blogs selecionados, especificamente na crônica em questão, foi admissível afirmar que há literatura nesses espaços virtuais e não apenas a transposição para esse ambiente, conferindo a essa literatura traços próprios.

\section{Considerações finais}

As novas tecnologias geram práticas sociais híbridas que estão diretamente ligadas à linguagem, por meio da qual também são difundidas. Nesse contexto, estão também os blogs, páginas personalizadas on-line que permitem o registro de informações de qualquer natureza, inclusive de literatura.

Os blogs de conteúdo literário tornaram-se uma boa alternativa para cidadãos comuns publicarem seus escri- 
tos, tanto pela gratuidade quanto pela facilidade de criação e manutenção. Eles passaram a ser o principal alvo de escritores da contemporaneidade. Contudo, falar da supressão do papel como único suporte para a literatura é mostrar indícios de características específicas para essa produção virtual.

A escrita nos blogs é mais breve, clara, direta e configura-se numa espécie de escrita oralizada, em tom mais próximo, atrativo e humano. Além disso, pode dialogar com imagens, vídeos, hipertextos, som, dentre outros recursos. O objetivo é atrair o leitor que, quase simultaneamente, pode opinar sobre o texto por meio de comentários nos blogs. Embora não tenham sido estudadas neste artigo, as páginas de comentários desses espaços virtuais podem caracterizar o ambiente como salas de discussão ou comunidades on-line, pela subjetividade e caráter relacional. Como em toda a blogosfera, para a literatura, é um recurso muito valioso, tendo em vista a possibilidade de troca de impressões, seja entre autor e leitor, autor e autor ou leitor e leitor.

Apesar da inovação para o campo literário, não é possível falar em redefinição de literatura, mas sim numa ampliação no campo de criação e atuação por parte desse novo autor. A internet disponibiliza opções diferenciadas de produção, divulgação e comercialização de literatura.

A qualidade dos textos está diretamente ligada à facilidade de lidar com $o$ sincretismo da linguagem que permeia o ambiente virtual. As características são, sim, específicas, pois há conteúdos na internet que só poderiam ser publicados nesse meio, onde os textos são concisos e nem a escrita nem a leitura são lineares.

Sobre autoria nesse meio, é importante ressaltar que ela é influenciada pelo contexto de produção e recepção. $\mathrm{O}$ autor trabalha a palavra, tira-a de seu lugar comum e surpreende o leitor de alguma forma na rede. Como autores de grandes obras, os autores de textos literários da blogosfera também podem ser entendidos como aqueles que, segundo Foucault (2010), dão à inquietante linguagem da ficção suas unidades, seus nós de coerência, sua inserção no real, uma vez que, unindo as antigas formas de expressão às possibilidades oferecidas pela rede eletrônica, ele consegue produzir sentidos.

Contemporary literature produced on the internet and the blogs: features and traces of authorship

\section{Abstract}

The present study consists of to analyze and characterize the literary text produced in the contemporary blogs, from the production of new authors who have emerged from this virtual space as support. After analysis of five chronicles, in which the traces of authorship and the work with the aesthetic function in the text were observed, it was found if that the blogs define different features to the contemporary literature on the internet.

Keywords: Blog. Authorship. Literature. 


\section{Nota}

1 A Literatura nos Blogs - $\mathrm{O}$ hipermodernismo já chegou (http://www.cronopios.com.br/site/ internet.asp?id=2265), retirado em 27/08/11.

\section{Referências}

ABREU, Ana Silvia Couto de. Gestos de escrita em ambientes virtuais - uma análise. Disponível em: <http://www.labeurb. unicamp.br/livroEurbano/pdf/eurbano5.pdf>. Acesso em: 16 set. 2011.

BARROS, Diana Luz Pessoa de. Dialogismo, polifonia e enunciação. In: BARROS,

Diana Luz Pessoa de; FIORIN, José Luiz (Orgs.). Dialogismo, polifonia e intertextualidade. 2. ed. São Paulo: Edusp, 2003.

BARROS, Eduardo Portanova. O autor imaginário da pós-modernidade: repensando Flusser e Foucault. Disponível em: <http:// www.unisinos.br/revistas/index.php/ciencias_sociais/article/view/479/75>. Acesso em: 19 set. 2011.

BOSI, Alfredo. História concisa da literatura brasileira. 43. ed. São Paulo: Cultrix, 2006.

CANDIDO, Antonio. O nacionalismo literário. In: Formação da literatura brasileira (Momentos decisivos). 4. ed. São Paulo: Martins, 1971. p. 9-22.

O Romantismo como posição do espírito e da sensibilidade. In: Formação $d a$ literatura brasileira (Momentos decisivos). 4. Ed. São Paulo: Martins, 1971. p. 23-34.

. As formas de expressão. In: Formação da literatura brasileira (Momentos decisivos). 4. ed. São Paulo: Martins, 1971. p. 35-43.

CANDIDO, Antonio. Literatura e sociedade. Rio de Janeiro: Ouro Sobre Azul, 2006.

CANDIDO, A. (1992). A vida ao rés-do-chão, in: CANDIDO, A. A crônica: o gênero, sua fixação e suas transformações no Brasil. Campinas: Ed. da Unicamp; Rio de Janeiro: Fundação Casa de Rui Barbosa, p. 13-22. O romantismo no Brasil. São Paulo: Humanitas, FFLCH/SP, 2004.

CAVALHEIRO, Juciane dos Santos. A concepção de Bahktin, Barthes e Foucault. Disponível em: <http://www.uel.br/revistas/uel/ index.php/signum/article/view/3042/2585>. Acesso em: 15 out. 2011.

COMPANHIA DOS BLOGUEIROS.(BLOG). Disponível em: <http://ciadosblogueiros.blogspot.com>. Acesso em: 14 maio 2011.

COUTINHO, Afrânio. Notas de teoria literária. Rio de Janeiro: Civilização Brasileira, 1978.

COUTINHO, Afrânio (Org.). A literatura no Brasil: era romântica. 3. ed. Rio de Janeiro: J. Olympio; Niterói: UFF, 1986.

. A literatura no Brasil. Rio de Janeiro: Sul Americana, 1968.

COMPAGNON, Antoine. A literatura. In: $O$ demônio da teoria: literatura e senso comum. Belo Horizonte: Editora da UFMG, 2003.

DANTO, Arthur C. Após o fim da arte: a arte contemporânea e os limites da história. São Paulo: Odysseus Editora/Edusp, 2006

DELABRE, Raúl Trejo. "Internet como expressão e extensão do espaço público”. In. Matrizes. Disponível em: <http://www.usp.br/ matrizes/MATRIZes_02_02_por.php>.Acesso em: 10 jun. 2011.

FACHINETTO, Lisiane. Subjetividade, escrita e autoria. Disponível em: <http://www.fundamentalpsychopathology.org/8_cong_anais/ TR_413.pdf> Acesso em: 28 ago. 2011.

FARIZATTO, Matheus. Virando jornalista. Disponível em: <http://virandojornalista. blogspot.com/>. Acesso em: 16 maio 2011.

FÉLIS, Claudia Cristina Gatti. Interação na internet: os blogs como uma nova for- 
ma de usar a linguagem. Disponível em: $<$ http://www.dominiopublico.gov.br/pesquisa/ DetalheObraForm.do?select_action=\&co_ obra=11377> . Acesso em: 1 out. 2011.

FIAD, Raquel Salek. Ensino e autoria. In. TFOUNI, Leda Verdiani. (Org.). Múltiplas faces da autoria. Ijuí: Ed. Unijuí, 2008.

FOUCAULT, Michel. Michel Foucault e o dilaceramento do autor. Disponível em: $<$ http://www.pucsp.br/margem/pdf/m16sm. pdf>. Acesso em: 10 ago. 2011.

. O que é um autor? 5. ed. Alpiarça: Passagens, 2002.

FOUCAULT, Michel. A ordem do discurso. São Paulo: Loyola, 2010. (Trad. Laura Fraga de Almeida).

GALLI, Fernanda Correa Silveira. Linguagem da Internet: um meio de comunicação global. In: MARCUSCHI, L. A.; XAVIER, A. C. dos S. (Org.). Hipertexto e gêneros digitais: novas formas de construção de sentido. 2. ed. Cortez, 2010, p. 147-164.

GOULART, Emilia. Emilia Goulart. Disponível em: <http://emiliagoulartsantos.blogspot. com/>. Acesso em: 12 maio 2011.

GREGOLIN, Maria do Rosário Valencise. A tipologia textual e a construção da referencialidade no discurso jornalístico. Trabalho apresentado no $16^{\circ}$ Congres International Des Linguistes, Paris, 1997.

HEWITT, Hugh. Blog: entenda a revolução que vai mudar o seu mundo. Tradução de Alexandre Martins Morais. Rio de Janeiro: Thomas Nelson Brasil, 2007.

HOUAISS, Antônio e VILLAR, Mauro de Salles. Dicionário Houaiss da língua portuguesa. Rio de Janeiro, Objetiva, 2001.

JENKINS, Henry. A cultura da convergência. Editora Aleph, 2009.

KOMESU, Fabiana. O que é um autor na internet? Disponível em: <http://www.celsul.
org.br/Encontros/06/Individuais/129.pdf> . Acesso em: 13/8/2011.

LAGES, Amanda Lemos. Por dentro do assunto. Disponível em: <http://www.bolgdoano.blogspot.com/>. Acesso em: 17 maio 2011.

LAVOYER, Rita. Blog Rita Lavoyer. Disponível em: <http://ritalavoyer.blogspot.com/>. Acesso em: 12 maio 2011.

LUCENI, Antonio. Antonio Luceni. Disponível em: <http://www.antonioluceni.blogspot. com/>. Acesso em: 20 jul. 2011.

MATOS, Adriana Dória. Escritores de blogs: a web como espaço de criação e discussão sobre literatura. Disponível em: <http://www. hipertextus.net/volume3/Adriana-Doria-MATOS.pdf>. Acesso em: 14 jul. 2011.

MATTOSO, Guilherme de Querós. Internet, jornalismo e weblogs: uma nova alternativa de informação. Disponível em: http://www. bocc.ubi.pt/pag/mattoso-guilherme-webjornalismo.pdf. Acesso em: 10 jun. 2011.

MARCONDES FILHO, Ciro. De como a cibernética pôs abaixo o mundo organizado como linguagem. In: Revista USP, n. 74, São Paulo, jun./ago., 2007.

MONTI, Carlo. Estrutura e partes da monografia e do TCC. Ribeirão Preto: Centro Universitário Barão de Mauá. Disponível em: <http://poshistoriacs.blogspot.com/search/ label/Downloads>. Acesso em: 02 nov. 2011.

. Padrões de referências. Ribeirão Preto: Centro Universitário Barão de Mauá. Disponível em: <http://poshistoriacs.blogspot.com/search/label/Downloads $>$. Acesso em: 02 nov. 2011.

MORAES, Dênis de. $O$ concreto e o virtual: mídia, cultura e tecnologia. Rio de Janeiro: DP\&A, 2001.

MULHERES CAFAJESTES. (BLOG). Disponível em: <http://www.mulherescafajestes. blogspot.com/>. Acesso em: 13 jun. 2011. 
ORDUÑA, Octavio I. Rojas [et al.]. Blogs: revolucionando os meios de comunicação. Trad. Vértice Translate; revisão técnica: Ana Carmem Thereza Faschini. São Paulo: Thomsom Learning, 2007.

ORLANDI, P. Eni. Análise de discurso - princípios e procedimentos. São Paulo: Pontes, 2001.

OLIVEIRA, Maria Regina Momesso de. Blogs jornalísticos: práticas de leitura participativa, democrática e crítica? In: Marlon Leal Rodrigues; Wedencley Alves. (Org.). Discurso e sentido: questões em torno da mídia, do ensino e da História. 1. ed. São Carlos, SP: Claraluz, 2007, v. 1, p. 101-122.

.Weblogs: a exposição de subjetividades adolescentes. In: SARGENTINI, Vanice. (Org.). Foucault e os domínios da linguagem: discurso, poder, subjetividade. São Carlos: Claraluz, 2004, v. 1, p. 201-214.

PLATÃO, José Luiz; SAVIOLI, Francisco Platão. Para entender o texto: leitura e redação. 3. ed. São Paulo: Ática, 1996.

POSSENTI, Sírio. O sujeito fora do arquivo: as múltiplas faces da linguagem. Brasília: Universidade de Brasília, 1996.

. Enunciação, autoria e estilo. In: Marlon Leal Rodrigues; Wedencley Alves. (Org.). Discurso e sentido: questões em torno da mídia, do ensino e da História. 1 ed. São Carlos, SP: Claraluz, 2007, v. 1, p. 13-24.

. Indícios de autoria. IN: Perspectiva (revista do centro de ciência da educação). Florianópolis, v. 20, n. 1, 2002, p. 105-123.

ORENSTEIN, Sylvia. Aqui entre nós. Disponível em: <http://sylorenstein.blogspot. com/>. Acesso em: 20 jul. 2011.

RODRIGUES, Antônio José. Antônio José Rodrigues. Disponível em: <http://www.antoniojoserodrigues.blogspot.com/>. Acesso em: 20 jul. 2011.
ROMÃO, Lucília Maria Sousa. O cavalete, a tela e a memória: considerações sobre a autoria na rede. DELTA. Documentação de Estudos em Linguística Teórica e Aplicada, São Paulo: v. 22, p. 303-328, 2006.

REIS, Carlos. $O$ conhecimento da literatura. 1. ed. Porto Alegre: EDIPUCRS, 2003.

REQUENA, Cristiano. Blog do Requena. Disponível em: <http://77requena.blogspot. com/>. Acesso em: 20 jul. 2011.

RESENDE, Eduardo. Pretextos-elr. Disponível em: <http://pretextoselr.blogspot.com/>. Acesso em: 16 ago. 2011.

SANTOS, Janete Silva dos. A função autor e os indícios de autoria. Disponível em: <http:// www.uff.br/feuffrevistaquerubim/images/ arquivos/artigos/a_funo_autor_e_indcios_de_ autoria.pdf,>. Acesso em: 19 set. 2011.

SCHITTINE, Denise. Blog: comunicação e escrita íntima na internet. Rio de Janeiro: Civilização Brasileira, 2004.

VIEGAS, Ana Cláudia. Escritas contemporâneas: literatura, internet e a "invenção de si”. Disponível em: <http://www.uff.br/ cadernosdeletrasuff/32/artigo4.pdf $>$. Acesso em: 15 set. 2011.

VIGGIANO, Eleonora. Literatura em bits A arte literária no meio virtual. Disponível em: <http://www.letras.ufrj.br/ciencialit/ encontro/Eleonora\%20texto\%20completo. doc>. Acesso em: 21 set. 2011.

WELLEK, René; WARREN, Austin. Teoria da literatura. Lisboa: Publicações Europa -América, 1971.

ZIVIANI, Rodrigo. Blog do Zivi. Disponível em: <http://rodrigozivi2.blogspot.com/>. Acesso em 12 maio 2011. http://www.textos-e-reflexoes.blogspot.com 